\title{
First-Principle Calculations for the Active Centers in Vanadium-Containing Chloroperoxidase and its Functional Models: Geometrical and Spectral Properties
}

\author{
TOMASZ BOROWSKI, ${ }^{1}$ WALDEMAR SZCZEPANIK, ${ }^{1}$ \\ MAKSYMILIAN CHRUSZCZ, ${ }^{1}$ EWA BROCŁAWIK ${ }^{2}$ \\ ${ }^{1}$ Faculty of Chemistry, Jagiellonian University, Ingardena 3, 30-060 Kraków, Poland \\ ${ }^{2}$ Institute of Catalysis and Surface Chemistry, Polish Academy of Sciences, \\ Niezapominajek, 30-239 Kraków, Poland
}

Received 11 December 2002; accepted 10 October 2003

Published online 19 May 2004 in Wiley InterScience (www.interscience.wiley.com). DOI 10.1002/qua.20040

\begin{abstract}
Vanadium-containing haloperoxidases (VXPOs) constitute a group of relatively newly discovered metalloenzymes catalyzing oxidation of halogen anions to hypohalous acids by hydrogen peroxide. The structures of their native and peroxide-bound forms as well as a reliable functional model system were characterized by X-ray diffraction crystallography methods. In this work, we focus on two well-characterized model systems and the active site itself of vanadium-containing chloroperoxidase from Curvularia inaequalis (VCPO). For the two model systems, we performed geometry optimization and frequency calculations at the B3LYP/LanL2DZ level of theory. In addition, the vertical energies and oscillator strengths for a few lowest electronic transitions were computed with TDDFT. The solvent effect on electronic transitions was modeled either by means of a few explicit water molecules hydrogen-bonded to studied complexes or by point charges representing them. As the active sites of VXPOs have to be modeled with additional charged groups of amino acids neutralizing the negative vanadium core, we restricted our calculations to DFT optimization and TDDFT calculations for excited states. In this paper, the results of these computations, namely, selected bond lengths and angles, vibrational frequencies, electronic transition energies, and oscillator strengths, are presented and compared with relevant literature data. This comparison, we believe, gives credits to the methodology and models used, which is also of importance for mechanistic considerations. ( 2004 Wiley Periodicals, Inc. Int J Quantum Chem 99: 864-875, 2004
\end{abstract}

Key words: haloperoxidases; active sites in VXPO; quantum chemical modeling; TDDFT; spectral properties 


\section{Holo Form}

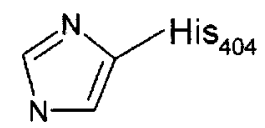

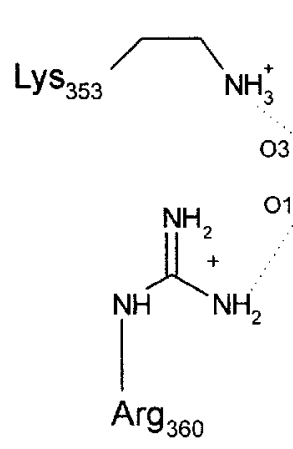

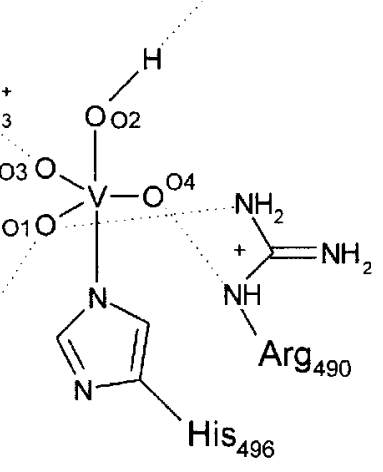

FIGURE 1. Active sites in holo- and peroxide-bound forms of chloroperoxidase from Curvularia inaequalis.

\section{Introduction}

V anadium-containing haloperoxidases (VXPOs) are enzymes that catalyze oxidation of halide $\left(\mathrm{X}^{-}=\mathrm{Cl}^{-}, \mathrm{Br}^{-}\right.$, or $\left.\mathrm{I}^{-}\right)$by hydrogen peroxide. As the formal charge of halogen changes from -1 to +1 , this process is an example of two-electron oxidation and usually results in halogenation of organic substrates [1]. The basic catalytic reaction catalyzed by these enzymes comprises oxidation of halides to their corresponding hypohalous acids by hydrogen peroxide (Eq. (1)).

$$
\mathrm{H}_{2} \mathrm{O}_{2}+\mathrm{H}^{+}+\mathrm{X}^{-} \rightarrow \mathrm{H}_{2} \mathrm{O}+\mathrm{HOX}
$$

The name of a particular haloperoxidase reflects the capability of the enzyme to oxidize halides. For example, chloroperoxidases catalyze oxidation of $\mathrm{Cl}^{-}$as well as $\mathrm{Br}^{-}$and $\mathrm{I}^{-}$. On the other hand, bromoperoxidases can oxidize only $\mathrm{Br}^{-}$and $\mathrm{I}^{-}$.

The crystal structures of vanadium-containing chloroperoxidase from the fungus Curvularia inaequalis (abbreviated here as VCPO) in its native and peroxide-bound forms have been solved by Messerschmidt and co-workers $[2,3]$. The active site of this enzyme accommodates one vanadate cofactor $\left(\mathrm{HVO}_{4}^{2-}\right)$ covalently bound to $\mathrm{His}_{496}$, and this coordination results in a trigonal-bipyramidal structure with three vanadate oxygens in the equatorial plane (Fig. 1). The two apical positions are occupied by a fourth vanadate oxygen and the $\mathrm{N} \varepsilon 2$ nitrogen of $\mathrm{His}_{496}$. Moreover, the negative charge on the vanadate moiety is neutralized by three cationic side chains of two arginines and one lysine, which form strong hydrogen bonds with equatorial oxygen atoms. As for the apical oxygen, it was originally assigned to a hydroxide group forming a hydrogen bond with $\mathrm{His}_{404}$. However, additional crystallographic studies for point mutants of this enzyme seemed to suggest that this apical ligand might be a water molecule [4].

The active site of the peroxide-bound form of chloroperoxidase contains vanadium $(\mathrm{V})$ ion coordinated by five ligands arranged in distorted tetragonal pyramid geometry. Two peroxide oxygens, the $\mathrm{N} \varepsilon 2$ nitrogen of $\mathrm{His}_{496}$ and one more vanadate oxygen (O3) constitute the basal plane. The apical ligand was identified as an oxo ligand (O4). As $\mathrm{His}_{404}$ is no longer hydrogen bonded to the vanadate center, it has been omitted from the diagram (Fig. 1).

In addition to the structural characterization of these active sites in chloroperoxidase, they were also examined with UV-vis absorption spectroscopy [5]. The native form of chloroperoxidase reveals a spectrum with one distinct absorption maximum around $315 \mathrm{~nm}\left(\varepsilon=2.8 \mathrm{mM}^{-1} \mathrm{~cm}^{-1}\right)$ and strong background absorption that starts at $280 \mathrm{~nm}$. The peroxide binding in the active site causes characteristic spectral changes. Firstly, the absorption around $315 \mathrm{~nm}$ is much weaker here $\left(\varepsilon=0.7 \mathrm{mM}^{-1}\right.$ $\left.\mathrm{cm}^{-1}\right)$; secondly, an additional small peak at $384 \mathrm{~nm}$ appears. The absorption experiments were performed by Renirie et al. not only for the native enzyme but also for several point mutants with crucial amino acids substituted by alanine. The 

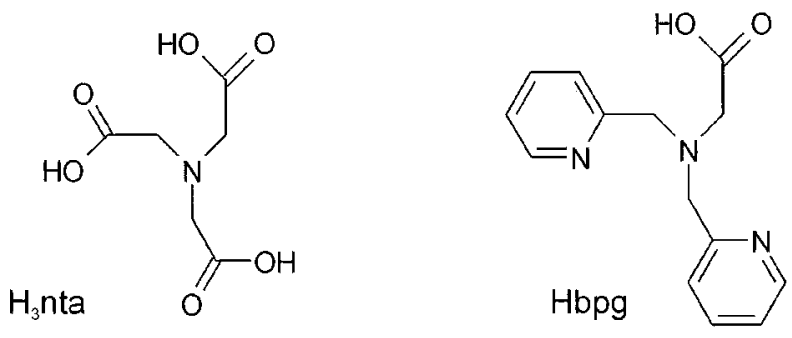

FIGURE 2. Chelating ligands from complexes $\left[\mathrm{VO}\left(\mathrm{O}_{2}\right) \mathrm{nta}\right]^{2-}-(1)$ and $\left[\mathrm{VO}\left(\mathrm{O}_{2}\right) \mathrm{bpg}\right]-(2)$.

most important conclusion drawn from results of these studies is that covalent bond between $\mathrm{His}_{496}$ and vanadate is indispensable for observation of these absorption bands. For example, a mutant of chloroperoxidase which has $\mathrm{His}_{496}$ substituted by alanine shows no absorption in the region of 300$400 \mathrm{~nm}$, and this fact was attributed to the lack of the $\mathrm{His}_{496}-\mathrm{V}$ covalent bond. Similarly, for mutants that have alanine instead of $\operatorname{Arg}_{490}$ and $\mathrm{Lys}_{353}$ no absorption band was observed in this spectral region, which suggests that these amino acids are necessary for appropriate binding of vanadate cofactor. Regarding the interpretation of the spectra, authors suggested that charge-transfer transition from the bound peroxide to the vanadium atom could be responsible for the absorption in peroxidebound form of chloroperoxidase. However, this assignment was not verified and the origin of the spectral feature in native VCPO was unclear.

For better understanding of the electronic structure and catalytic mechanism of the active sites in vanadate-containing haloperoxidases many excellent functional models were synthesized and characterized by several research groups [6, 7]. Because in this work we have focused on two selected model compounds, only these particular systems are briefly described here. They belong to the group of model systems studied by Colpas et al. [8], and we chose $\left[\mathrm{VO}\left(\mathrm{O}_{2}\right) \mathrm{nta}\right]^{2-}(\mathbf{1})$ and $\left[\mathrm{VO}\left(\mathrm{O}_{2}\right) \mathrm{bpg}\right](\mathbf{2})$, with the following abbreviations: $\mathrm{H}_{3}$ nta, nitrilotriacetic acid; Hbpg, $N, N$-bis(2-pyridylmethyl)glycine. These two particular complexes were selected because they differ in total charge and the character of donating atoms in chelating ligands (Fig. 2). The crystal structure of these compounds (potassium salt for 1) was solved, and their spectral properties were examined with IR and UV-vis spectroscopy methods. Infrared spectra revealed characteristic band for $\mathrm{V}-\mathrm{O}_{2}$ and $\mathrm{V}=\mathrm{O}$ groups around 560, 920, and $950 \mathrm{~cm}^{-1}$ and isotope effect upon substitution of peroxide oxygens with ${ }^{18} \mathrm{O}$ was measured for compound 1. As for the electronic spectra, both 1 and 2 showed one distinct absorption maximum around $2.9 \mathrm{eV}$ in water or $2.8 \mathrm{eV}$ in acetonitrile, and this feature was assigned to the peroxo-to-vanadium charge-transfer transition.

Reliable calculation of excitation energies in molecular systems was long considered to be a daunting task, where highly correlated methods were indispensable. At present, however, a relatively robust and reliable method became available, namely time-dependent DFT $[9,10]$ (TDDFT), which can be used for real molecular systems. This method was shown to give excitation energies for a wide range of organic and inorganic systems with errors up to $0.3-0.4 \mathrm{eV}$ [11-13] and was also successfully used in studies on metallic centers of enzymes [14].

To the best of our knowledge, there exist in literature only a few theoretical works on models for the active site of vanadium-dependent haloperoxidases, and not one of them concerns spectral properties. Conte and Bortolini have employed RHF and DFT methods in addition to NMR and ESI-MS techniques to study water coordination and the influence of the apical ligand on the structure and relative stabilities of vanadium peroxo species and to address preferences in protonated states [1517].

Because VXPOs are very interesting enzymes for which any theoretical studies comprise simplified models and concern only structural and energetic properties, we have undertaken quantum chemical studies for reliable models for active sites in these proteins aimed at their spectral properties. Thus, in subsequent sections we present results obtained for the models and compare them with experimental data where possible. We hope that the results presented in this paper will help in better understanding of electronic structure of vanadium centers and will constitute a good starting point for theoretical calculations aimed at catalytic mechanism of VXPOs.

\section{Methodology}

\subsection{MODELS}

The geometry of the model complexes $\left[\mathrm{VO}\left(\mathrm{O}_{2}\right) \mathrm{nta}^{2-}(\mathbf{1})\right.$ and $\left[\mathrm{VO}\left(\mathrm{O}_{2}\right) \mathrm{bpg}\right]$ (2) were obtained from the Cambridge Structural Database (CSD version 5.21, entries HABBOB and ZUSKIH). 
We have averaged bond lengths and angles so as to impose $C_{s}$ symmetry. With this symmetry constraint, these models were fully optimized.

For the models of active sites of chloroperoxidase from $C$. inaequalis we decided to chose vanadium cofactor and the most important fragments of the charged amino acids hydrogen-bonded with it. Thus, histidine was modeled by an imidazole ring, arginine by a guanidine cation, and lysine by methylamine. The initial coordinates of studied models were taken from structures deposited in the Protein Data Bank (entries 1VNI and 1IDU). Because the protonation state of $\mathrm{His}_{404}$ and some of the oxygen ligands remains unclear, we optimized and analyzed two models for each species differing in the number of protons on the cluster. The geometry of the models was optimized in a vacuum with no constraints.

\subsection{QUANTUM CHEMICAL CALCULATIONS}

All first-principle computations were done with Gaussian 98 (Revision A.11) [18]. Molecular structures and orbitals were drawn with the programs Cerius $^{2}$ [19] and MOLDEN [20].

In all DFT computations, the three-parameter exchange-correlation functional (B3LYP) due to Becke [21] was employed together with one of the basis sets described below. The first one, denoted here as BS1, consisted of the LanL2DZ basis by Ward and Hay [22, 23] on the $\mathrm{V}$ atom and the D95 basis set due to Dunning [24] for H, C, N, and O atoms. This basis set (BS1) was used in all geometry optimizations and frequency computations, as it proved to give reliable and fairly accurate results for these properties [25] while being computationally modest. The second basis set (BS2), used only in TDDFT electronic excitation calculations, consisted of $6-311+G(d)$ basis set on vanadium atom and $6-31+G(d)$ basis set for other elements. Thus, this basis set of triple- $\zeta$ quality on $\mathrm{V}$ atom and double- $\zeta$ on other atoms contained also polarization functions on all non-hydrogen atoms supplemented by one set of diffuse functions. This relatively large basis set should by flexible enough to model electronic structure of studied complexes. In TDDFT calculations for models with atomic charges representing hydrating water molecules, charges taken from the AMBER [26] force field were used.

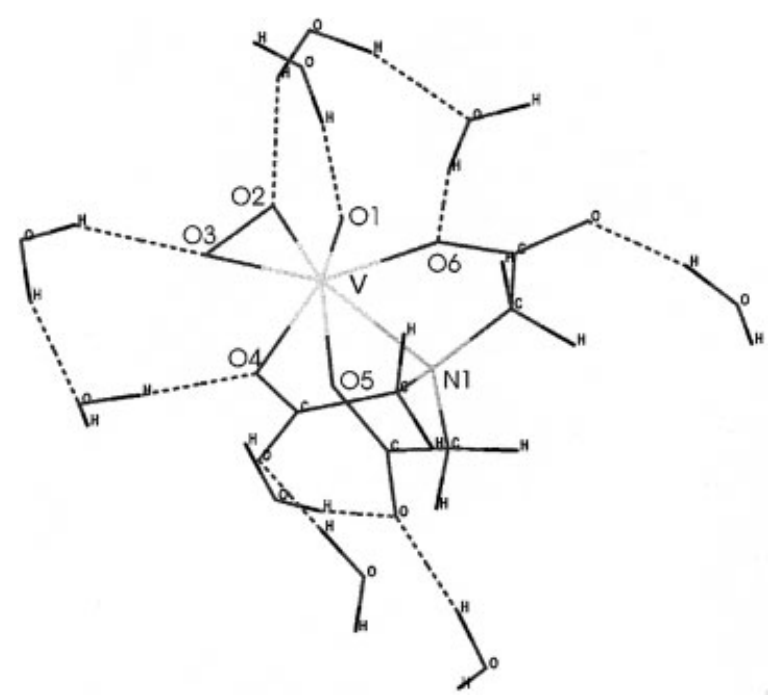

FIGURE 3. Optimised structure of solvated $\left[\mathrm{VO}\left(\mathrm{O}_{2}\right) \text { nta }\right]^{2-}\left(\mathbf{1} \mathrm{H}_{2} \mathrm{O}\right)$.

\section{Results and Discussion}

\subsection{MODEL SYSTEMS}

\section{Geometrical Structure}

The models for $\mathbf{1}$ and $\mathbf{2}$ were optimized in vacuum with $C_{s}$ symmetry imposed on the geometry and electronic density. Because we wanted to estimate the solvent effect on electronic spectrum, second optimization was performed for a supermolecular system consisting of $\mathbf{1}$ and $\mathbf{2}$ with hydrogenbonded water molecules. For practical reasons the number of solvating water was limited, thus we decided to add only one water molecule per oxygen atom. This particular solvent model was motivated by the results of Serrano-Andres et al., who showed that hydrogen-bonded solvent molecules should be explicitly included in calculations [27]. These solvent molecules were initially placed and oriented so at to facilitate hydrogen bonding to the solute and to maintain the $C_{s}$ symmetry. Subsequently, full geometry optimization was performed for two supermolecular systems denoted here as $\left(\mathbf{1} \mathrm{H}_{2} \mathrm{O}\right)$ and $\left(2 \mathrm{H}_{2} \mathrm{O}\right)$. The structures of optimized complexes $\mathbf{1}$ and $\mathbf{2}$ with solvating water are depicted in Figures 3 and 4, respectively. The atomic labels shown there should help the reader to analyze Table I, in which selected bond lengths and angles were compiled for optimized and experimental structures. Inspection of this table shows that, in most cases, agreement 


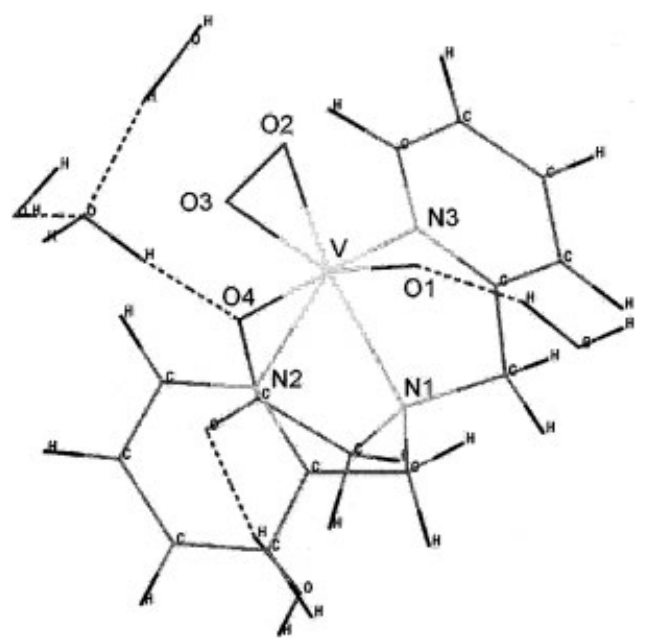

FIGURE 4. Optimised structure of solvated $\left[\mathrm{VO}\left(\mathrm{O}_{2}\right) \mathrm{bpg}\right]\left(2 \mathrm{H}_{2} \mathrm{O}\right)$.

between theoretically determined and experimental geometry parameters is generally satisfactory. Bond lengths differ by few hundredths of $\AA$ and angles by few degrees. However, some non-negligible differences appear for $\mathrm{V}-\mathrm{N} 1$ in the case of $\mathbf{1}$ and $\mathbf{2}$ and, to some extent, for the V-O6 bond in $\mathbf{1}$. The source of this discrepancy up to $0.15 \AA$ is not clear. It may be partially rationalized by the analy- sis of vibrational spectra discussed in the next paragraph. The two structures differ mostly in the geometry of the chelating ligand.

\section{Spectral Properties}

For structures of $\mathbf{1}$ and $\mathbf{2}$ optimized in a vacuum, we have performed frequency calculations with the same level of theory (B3LYP/BS1). The average error for frequencies calculated with this method was shown to be of the order of $40-50 \mathrm{~cm}^{-1}$ for small inorganic molecules [25], and this level of accuracy seems acceptable for systems of the size as the studied here complexes. The results of the IR calculations are compared with experimentally determined frequencies in Table II, and indeed one may observe that the discrepancy between absolute values of calculated and measured frequencies is of the order of $20-70 \mathrm{~cm}^{-1}$. Nevertheless, the shift of frequencies upon isotope substitution is perfectly reproduced. Thus, although the force constants are somewhat overestimated, the molecular force field seems to be modeled well with the assumed methodology. Furthermore, our calculations confirm the assignments for these frequencies proposed by Colpas et al. [8], which are indicated in Table II.

Quite interestingly, inspection of the results if IR computations revealed that one of the low-fre-

TABLE I

Selected distances $(\AA \AA)$ and angles for optimized and crystal structures of $\left[\mathrm{VO}\left(\mathrm{O}_{2}\right) \mathrm{nta}^{2-}(1)\right.$ and $\left[\mathrm{VO}\left(\mathrm{O}_{2}\right) \mathrm{bpg}\right]$ (2); atom labels in 2 given in parentheses.

\begin{tabular}{|c|c|c|c|c|c|c|}
\hline & \multicolumn{3}{|c|}{1} & \multicolumn{3}{|c|}{2} \\
\hline & Crystal & Opt (vac) & Opt $\left(\mathrm{H}_{2} \mathrm{O}\right)$ & Crystal & Opt (vac) & Opt $\left(\mathrm{H}_{2} \mathrm{O}\right)$ \\
\hline V-O1 & $1.610(5)$ & 1.626 & 1.626 & $1.615(2)$ & 1.620 & 1.620 \\
\hline $\mathrm{V}-\mathrm{O} 2$ & $1.866(4)$ & & & $1.864(2)$ & & \\
\hline $\mathrm{V}-\mathrm{O} 3$ & $1.865(3)$ & 1.866 & 1.860 & $1.869(2)$ & 1.868 & 1.867 \\
\hline V-O4 (N2) & $2.042(4)$ & & & $2.138(2)$ & & \\
\hline V-O5 (N3) & $2.051(4)$ & 2.086 & 2.063 & $2.148(2)$ & 2.150 & 2.141 \\
\hline V-O6 (O4) & $2.190(4)$ & 2.091 & 2.080 & $2.085(2)$ & 2.011 & 2.093 \\
\hline $\mathrm{V}-\mathrm{N} 1$ & 2.172 & 2.323 & 2.313 & $2.217(2)$ & 2.334 & 2.255 \\
\hline O2-03 & 1.433(6) & 1.495 & 1.487 & $1.424(2)$ & 1.476 & 1.478 \\
\hline O1-V-O2 & $104.3(2)$ & & & 103.95(9) & & \\
\hline O1-V-O3 & $105.1(2)$ & 105.7 & 105.9 & 104.70(9) & 105.8 & 104.4 \\
\hline $\mathrm{O} 2-\mathrm{V}-\mathrm{O} 3$ & 45.2(2) & 47.2 & 47.1 & 44.84(7) & 46.5 & 46.6 \\
\hline $\mathrm{O} 1-\mathrm{V}-\mathrm{O} 4$ (N2) & $95.3(2)$ & & & $92.57(9)$ & & \\
\hline O1-V-O5 (N3) & $93.4(2)$ & 91.7 & 92.1 & $91.94(10)$ & 91.6 & 94.3 \\
\hline O1-V-N1 & $90.8(2)$ & 83.1 & 83.2 & 87.36(8) & 81.2 & 84.4 \\
\hline O1-V-O6 (O4) & 167.0(2) & 158.7 & 158.8 & $164.35(8)$ & 156.3 & 161.2 \\
\hline (N2) O4-V-O5 (N3) & $149.2(1)$ & 147.9 & 147.8 & $149.70(7)$ & 148.2 & 146.7 \\
\hline (O4) O6-V-N1 (N1) & $76.8(1)$ & 75.6 & 75.6 & $77.00(6)$ & 75.1 & 74.5 \\
\hline
\end{tabular}


TABLE II

\begin{tabular}{|c|c|c|c|c|}
\hline \multicolumn{5}{|c|}{$\begin{array}{l}\text { Experimental }{ }^{\mathrm{a}} \text { and calculated frequencies }\left(\mathrm{cm}^{-1}\right) \text { for } \\
\mathrm{V}-\mathrm{O}_{2} \text { and } \mathrm{V}=\mathrm{O} \text { groups in }\left[\mathrm{VO}\left(\mathrm{O}_{2}\right) \text { nta }\right]^{2-}(1) \text { and } \\
{\left[\mathrm{VO}\left(\mathrm{O}_{2}\right) \text { bpg] (2); shifts upon isotope substitution }\right.} \\
\text { given in parentheses. }\end{array}$} \\
\hline \multicolumn{2}{|c|}{ Experimental } & \multicolumn{2}{|c|}{ Calculated } & \multirow[b]{2}{*}{ Assignment } \\
\hline${ }^{16} \mathrm{O}_{2}$ & ${ }^{18} \mathrm{O}_{2}$ & ${ }^{16} \mathrm{O}_{2}$ & ${ }^{18} \mathrm{O}_{2}$ & \\
\hline \multicolumn{5}{|c|}{ Compound 1} \\
\hline $\begin{array}{l}920 \\
950\end{array}$ & $\begin{array}{l}542(-21) \\
870(-50) \\
950(0)\end{array}$ & $\begin{array}{l}524.4 \\
588.6 \\
945.3 \\
996.2\end{array}$ & $\begin{array}{l}504.4(-20) \\
570.6(-18) \\
895.0(-50.3) \\
996.2(0)\end{array}$ & $\begin{array}{l}\text { Asym } \mathrm{V}-\mathrm{O}_{2} \\
\text { Sym } \mathrm{V}-\mathrm{O}_{2} \\
\mathrm{O}-\mathrm{O} \\
\mathrm{V}=\mathrm{O}\end{array}$ \\
\hline \multicolumn{5}{|c|}{ Compound 2} \\
\hline 571 & - & $\begin{array}{l}541.7 \\
595.0\end{array}$ & $\begin{array}{l}524.0(-17.7) \\
577.6(-17.4)\end{array}$ & $\begin{array}{l}\text { Asym } \mathrm{V}-\mathrm{O}_{2} \\
\text { Asym } \mathrm{V}-\mathrm{O}_{2}\end{array}$ \\
\hline 910 & - & 976.8 & $923.6(-53.2)$ & $\mathrm{O}-\mathrm{O}$ \\
\hline 947 & - & 1006.1 & $1006.1(0)$ & $\mathrm{V}=\mathrm{O}$ \\
\hline
\end{tabular}

a Taken from [8].

quency vibrations (around $200 \mathrm{~cm}^{-1}$ ) takes place along a symmetric normal mode which engages $\mathrm{V}-\mathrm{N}$ bond stretching and $\mathrm{O} 1-\mathrm{V}-\mathrm{O} 6, \mathrm{O} 4-\mathrm{V}-\mathrm{O} 5$, and $\mathrm{O} 1-\mathrm{V}-\mathrm{N} 1$ angles opening. Inspection of the data in Table I shows that, indeed, two of these three angles (O1-V-O6 and O1-V-N1) are considerably larger in the crystal structure. Thus, we propose that crystal packing distorts studied complexes and that distortion takes place mostly along this soft coordinate. This scenario seems plausible taking into account low frequency for this mode. From inspection of Table I, one may also conclude that presence of solvating molecules disturbs the geometry of complexes only to a very small extent. This holds true for both anionic (1) and neutral (2) complexes.

The electronic transitions were calculated by TDDFT methodology for three different schemes for the two model systems. Two of them consisted of an optimized complex with or without solvating water molecules. In the third one, molecules of the solvent were represented by atomic point charges taken from AMBER force field. Even if the last model was very simplified, it was taken into consideration because it is essentially no more computationally demanding than a solvent-free one, and it could bring some insight into the solvent effects. Representing solvent molecules by point charges was shown to be a promising tool in calculations of spectral properties for biological systems [28], even if a similar procedure (embedded cluster calculation) failed to reproduce absorption spectra for transition metals in ionic (halide and oxide) environments $[29,30]$. However, we are fully aware that modelling only a few selected solvent molecules by point charges is very crude and may bring only qualitative information. In Table III we gathered the calculated vertical excitation energies together with oscillator strengths for the lowest energy electronic transitions.

Comparison of the results obtained for $\mathbf{1}$ within TDDFT scheme and with two different basis sets shows that both excitation energies and oscillator strengths did not depend to a large extent on the choice of the basis set. Thus, qualitatively meaningful results can be obtained even with a relatively compact and inexpensive basis set, BS1, which was also shown to give reasonably good results in TDDFT calculations for the VO molecule [13]. In the case of spectra calculated with the time-dependent DFT method, irrespective of the basis set used, only one transition has considerable oscillator strength. For both studied complexes, this transition corresponds to the excitation from the ground to the first excited state of $\mathrm{A}^{\prime}$ symmetry $\left(\mathrm{X}^{1} \mathrm{~A}^{\prime} \rightarrow \mathrm{a}^{1} \mathrm{~A}^{\prime}\right)$ and the only difference between $\mathbf{1}$ and $\mathbf{2}$ is the energy of the first excited state of $\mathrm{A}^{\prime \prime}$ symmetry. For $\mathbf{1}$, this state $\left(\mathrm{a}^{1} \mathrm{~A}^{\prime \prime}\right)$ lies ca. $0.1 \mathrm{eV}$ below and for $2 \mathrm{ca} .0 .1 \mathrm{eV}$ above the $\mathrm{a}^{1} \mathrm{~A}^{\prime}$ state.

At first sight, the agreement of TDDFT results with experiment seems to be very good for both studied complexes. The energy of the intense electronic transition is reproduced with error smaller then $0.1 \mathrm{eV}$ (BS2), and the character of orbitals engaged in this excitation supports its peroxide-to-vanadium charge transfer assignment. In Figure 5, relevant molecular Kohn-Sham orbitals are depicted.

The lowest excited state of ${ }^{1} \mathrm{~A}^{\prime \prime}$ symmetry has smaller oscillator strength than the two ${ }^{1} \mathrm{~A}^{\prime}$ states, and this finding results seems to suggest that the a ${ }^{1} \mathrm{~A}^{\prime}$ state has minor contribution to the observed transition around $2.9 \mathrm{eV}$.

Thus TDDFT methodology clearly indicates that the intense electronic transition in $\mathbf{1}$ takes place from the ground to the first excited state of ${ }^{1} \mathrm{~A}^{\prime}$ symmetry.

As for the solvent effect modeled for $\mathbf{1}$ by explicit water molecules, the magnitude of the calculated solvatochromic shift is very small with respect to energies and oscillator strengths. It also seems apparent from the numerical values gathered in Table III that the simple point-charge model gives in most cases shifts of excitation energies in proper direction, but their magnitude is somewhat exaggerated. 
TABLE III

Excitation energies and oscilator strengths for low-energy electronic transitions for model compounds in $\left[\mathrm{VO}\left(\mathrm{O}_{2}\right) \text { nta] }\right]^{2-}(1)$ and $\left[\mathrm{VO}\left(\mathrm{O}_{2}\right) \mathrm{bpg}\right](2)$

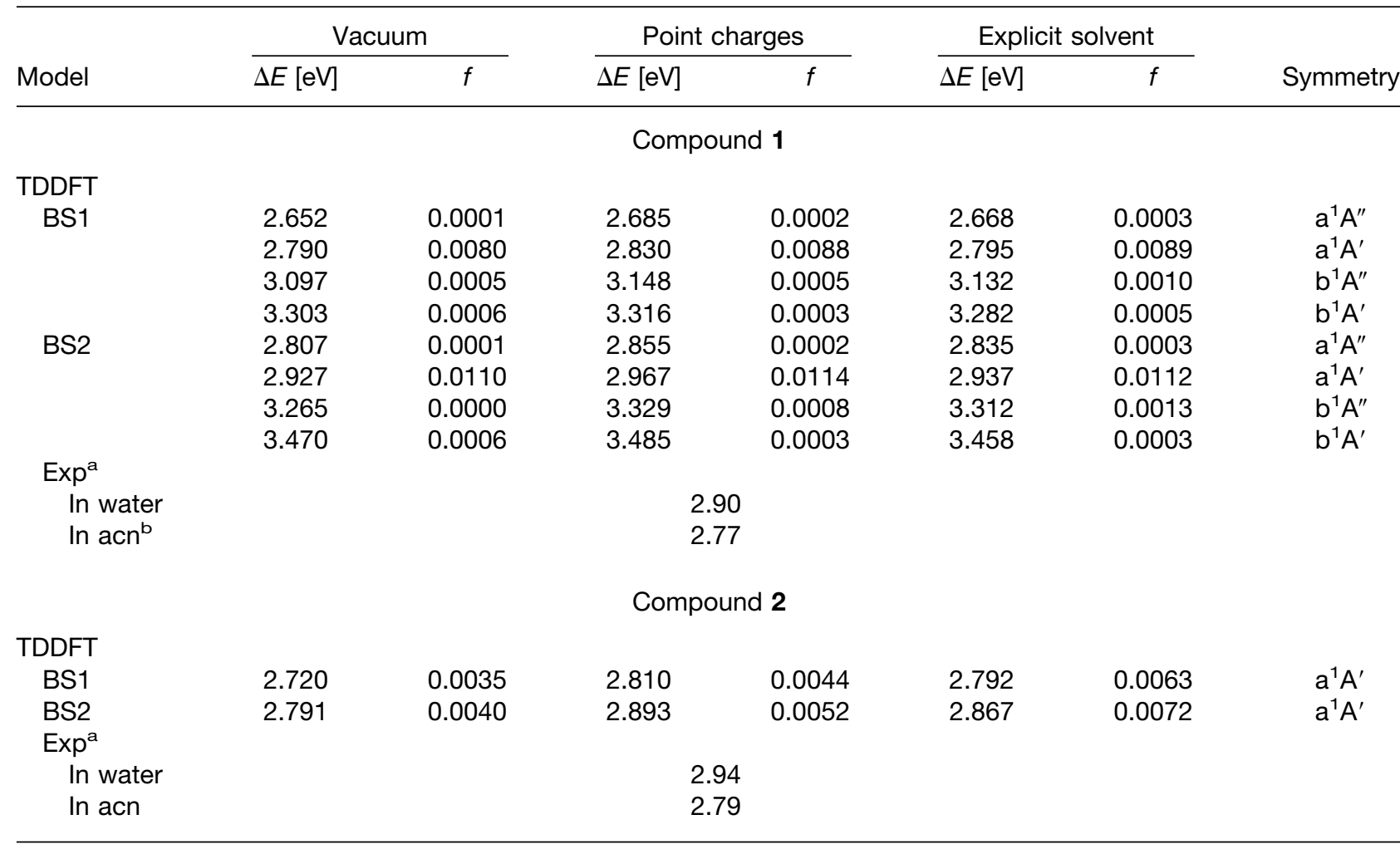

a Taken from [8].

${ }^{\mathrm{b}}$ acn, acetonitrile.

Quite interestingly, the calculated solvent effect is considerably stronger for neutral compound 2 . Here, the excitation energy changes from 2.79 to
2.87 upon including a few water molecules in calculations, and the oscillator strength almost doubles its magnitude.
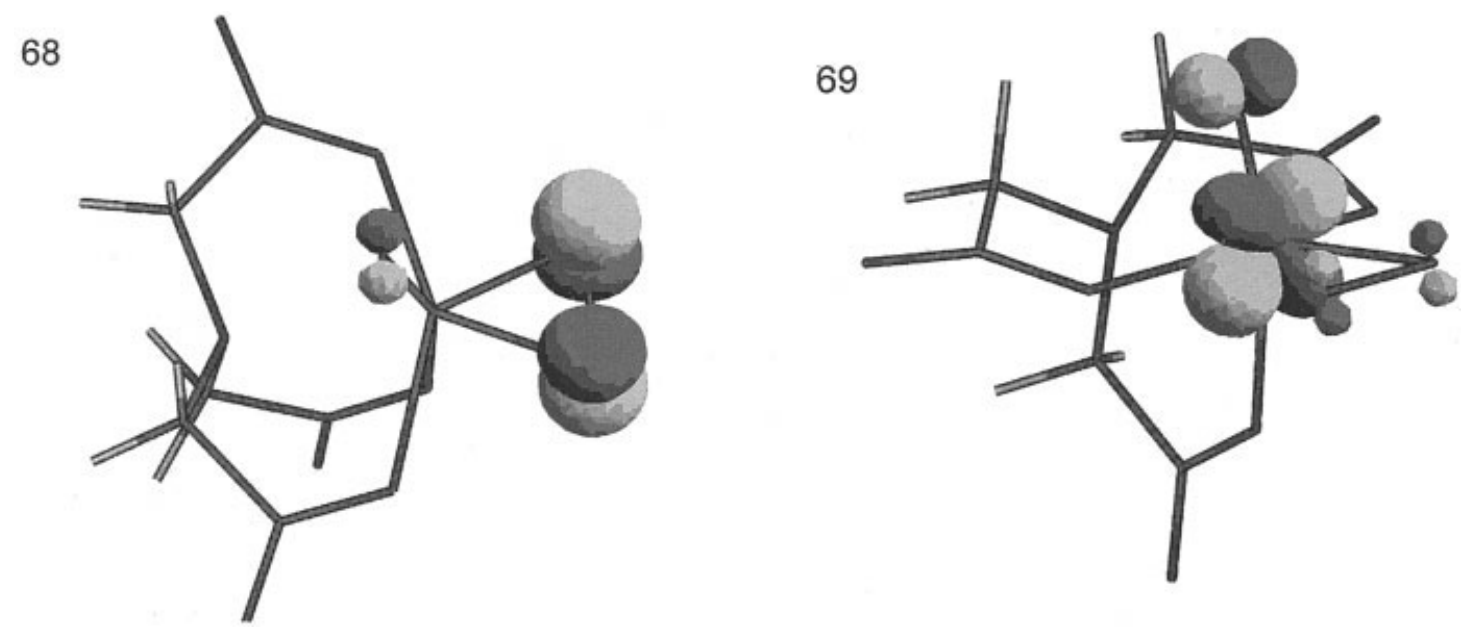

FIGURE 5. HOMO and LUMO Kohn-Sham orbitals engaged in the intense electronic transition (TDDFT calculations for (1)). 

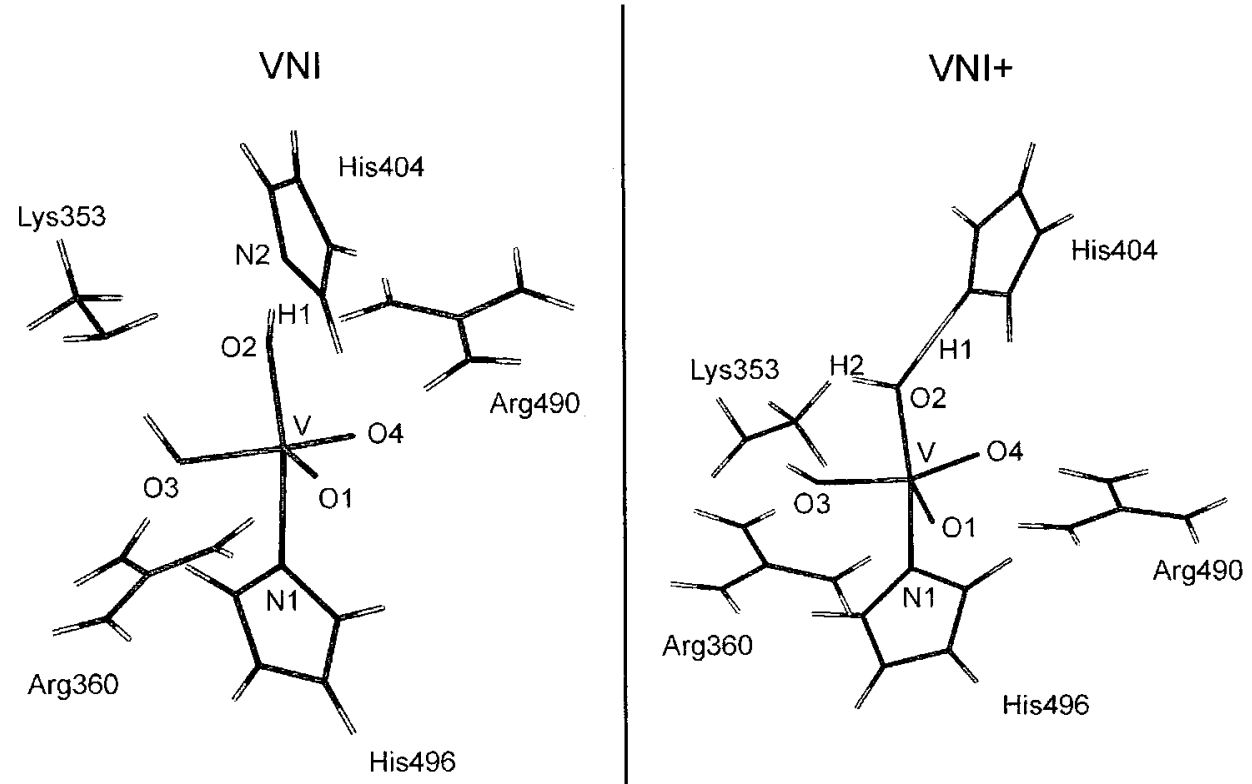

FIGURE 6. Optimised structures of $\mathrm{VNI}$ and $\mathrm{VNI}+$ models.

Thus, in light of the results presented above, the observed absorption for compound $\mathbf{1}$ in the region of $2.8 \mathrm{eV}$ in acetonitrile and $2.9 \mathrm{eV}$ in water should be due to excitation within ${ }^{1} \mathrm{~A}^{\prime}$ manifold. Because the positions of absorption maxima in $\mathrm{ACN}$ and water differ significantly, and for more polar water it is shifted to higher energies, one may expect an appreciable change in excitation energy when going from vacuum to water. Inspection of the results presented in Table III reveals that the simplest models of solvent effects suggest destabilization of a ${ }^{1} \mathrm{~A}^{\prime}$ excited states with respect to the ground state. Although this effect is rather small, the direction of the change is correctly predicted and agrees with experimental findings.

In conclusion, TDDFT methodology identified the $\mathrm{X}^{1} \mathrm{~A}^{\prime} \rightarrow \mathrm{a}^{1} \mathrm{~A}^{\prime}$ transition as the one responsible for an intense absorption band. Furthermore, the solvation effects were identified to be the most probable cause of the differences between calculated and experimentally observed absorption energies.

\subsection{ACTIVE SITES IN CHLOROPEROXIDASE}

\section{Geometrical Structure}

The optimized structures of the two models for the active site in holochloroperoxidase are pre- sented in Figure 6. The optimization for the model labeled as VNI was performed with the protonation state of vanadium ligands proposed by the authors of this structure [3]. Thus, the apical oxygen ligand in this model was a hydroxide group, and all of the equatorial oxygens were hydrogen bonded with positively charged second-shell ligands. However, as already observed by Rehder et al. [31], this axial ligand might easily change from $\mathrm{OH}$ to $\mathrm{H}_{2} \mathrm{O}$, and this flexibility of its character could by important for catalytic reaction mechanism. Moreover, Messerschmidt et al. [3] proposed that hydrogen bonding with $\mathrm{His}_{404}$ activates the apical $\mathrm{OH}$ group for the deprotonation of hydrogen peroxide, one of the substrates of chloroperoxidase. Thus, it was of considerable interest to verify the identity of the apical ligand and to assess to what extent it might be activated by hydrogen bonding to $\mathrm{His}_{404}$. With this aim in mind we have optimized also the second model of the active site in VCPO, labeled VNI+, where the apical oxygen ligand was a water molecule hydrogen bonded with $\mathrm{His}_{404}$.

Selected bond lengths for the two optimized models are compared with appropriate crystallographic data in Table IV. Bond lengths from two different crystal structures are reported. 1VNI corresponds to the recombinant holoenzyme while IIDQ corresponds to the native chloroperoxidase 
TABLE IV

Selected bond lengths $(\AA)$ for active sites in holochloroperoxidase.

\begin{tabular}{lccccc}
\hline & \multicolumn{2}{c}{ Calculations } & & \multicolumn{2}{c}{ Crystal structure } \\
\cline { 2 - 3 } Bond & VNI & VNI+ & & 1VNI & 1IDQ \\
\hline V-O1 & 1.65 & 1.66 & 1.60 & 1.63 \\
V-O3 & 1.87 & 1.82 & 1.60 & 1.61 \\
V-O4 & 1.66 & 1.65 & 1.61 & 1.60 \\
V-O2 & 1.91 & 1.96 & & 2.17 & 1.88 \\
V-N1 & 2.19 & 2.16 & & 1.94 & 2.07 \\
O2-H1 & 1.02 & 1.34 & & - \\
H1-N2 & 1.72 & 1.16 & & - \\
O2-N2 & 2.74 & 2.50 & & 3.23 & - \\
O2-H2 & - & 0.97 & & - & - \\
\hline
\end{tabular}

from C. inaequalis. The analysis of the data gathered in Table IV shows that the calculated distance $\mathrm{V}-\mathrm{O} 2$ fits between the crystallographic data. Accordingly, in VNI model this distance is only $0.03 \AA$ longer than in $1 \mathrm{IDQ}$, whereas in VNI+ this bond is $0.21 \AA$ shorter than in 1VNI structure. The larger discrepancy between calculated (in vacuum) and experimental (the whole protein) structures in the case of $\mathrm{H}_{2} \mathrm{O}$ ligand (in comparison with $\mathrm{OH}$ ) is comprehensible if one takes into account the difference in strength of the bonds with vanadium atom for $\mathrm{OH}$ and $\mathrm{H}_{2} \mathrm{O}$. A hydrogen bond involving water molecule may relatively easily stretch the weaker $\mathrm{V}-\mathrm{OH}_{2}$ bond. Thus these observations seem to corroborate the proposition that the apical ligand might formally correspond to water molecule making relatively strong hydrogen bond with $\mathrm{His}_{404}$. Indeed, the lengths of the $\mathrm{O} 2-\mathrm{H} 1$ and $\mathrm{H} 1-\mathrm{N} 2$ bonds

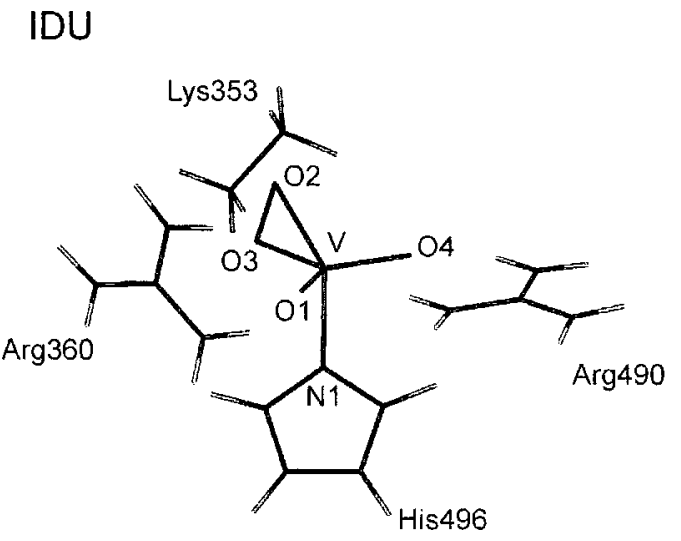

show that in the case of VNI+ model we have a positively charged protonated $\mathrm{His}_{404}$ bonded with the hydrogen apical $\mathrm{OH}$ group, i.e., one of the water protons migrated to the $\mathrm{His}_{404}$ nitrogen. At the same time, the O2-N2 distance is considerably longer for VNI than for VNI+ model, which could indicate that the $\mathrm{OH}$ group itself is not activated by non-protonated $\mathrm{His}_{404}$.

In the course of the optimization procedure, one of the protons migrated from amine group $\mathrm{Lys}_{353}$ to the first shell oxygen ligand (which could be the artifact of our model), and this migration occurred for both studied models. As a result of this proton shift, the V-O3 bond length increases by $0.2-0.3 \AA$ relative to the crystal structures. This bond makes the only exception in the overall agreement between calculated and experimental structural parameters.

Two models depicted in Figure 7 were selected to simulate the peroxide-bound form of chloroperoxidase. The IDU model represents the structure known from crystallographic studies. In addition, the IDU+ model with one of the peroxide oxygen atoms protonated, represents the structure proposed to be involved in a catalytic cycle. For both of these models selected bond lengths are compared with crystallographic data in Table V. Comparison of the data for IDU model and 1IDU crystal structure reveals an overall good agreement between them. The only exception is the V-O1 bond, which is almost $0.3 \AA$ longer for the crystal structure than for the calculated structure. The source of this difference is uncertain, but the bond length of $1.93 \AA$ seems very unlikely for a $\mathrm{V}=\mathrm{O}$ group. Protonation of one from peroxide oxygen atoms taken into ac-

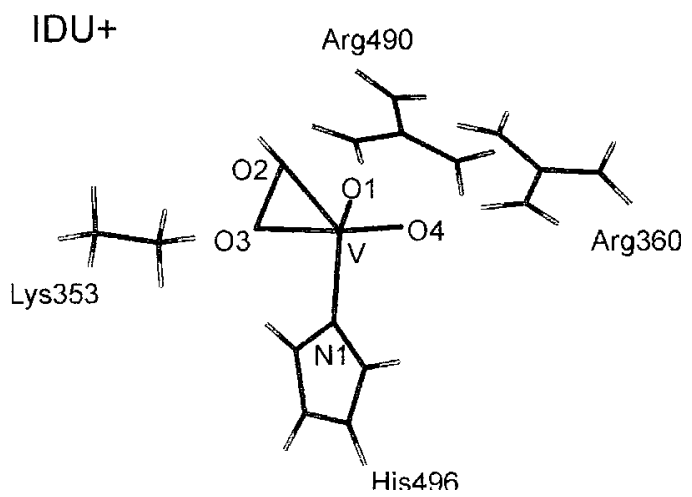

FIGURE 7. Optimised structures of IDU and IDU+ models. 
TABLE V

Selected bond lengths $(\AA)$ for active sites in peroxide-bound chloroperoxidase.

\begin{tabular}{llcc}
\hline & \multicolumn{2}{c}{ Calculations } & $\begin{array}{c}\text { Crystal } \\
\text { structure }\end{array}$ \\
\cline { 2 - 3 } Bond & IDU & IDU + & 1IDU \\
\hline V-O1 & 1.66 & 1.62 & 1.93 \\
V-O2 & 1.87 & 2.10 & 1.86 \\
V-O4 & 1.64 & 1.62 & 1.60 \\
V-O3 & 1.93 & 1.98 & 1.89 \\
V-N1 & 2.05 & 2.00 & 2.19 \\
O2-O3 & 1.53 & 1.53 & 1.47 \\
\hline
\end{tabular}

count in IDU + model causes significant elongation of the $\mathrm{V}-\mathrm{O} 3$ bond, but other bond lengths change only slightly compared to the IDU structure. Nevertheless, one could speculate that the long $\mathrm{V}-\mathrm{O}$ bond reported in crystal structure might be possibly attributed to the protonated oxygen.

\section{Spectral Properties}

For the four models of active sites in chloroperoxidase described above we performed TDDFT calculations in order to gain the insight into the character of electronic transitions giving rise to the observed absorption bands.

The resulting calculated absorption spectra are depicted in Figures 8 and 9 for holo- and peroxidebound chloroperoxidase models, respectively. For the holo-forms, one may observe a shift to higher energies upon protonation of the apical hydroxide group and a significant drop in intensity (oscillator strengths) for the lowest energy transitions (see VNI and VNI+ spectra in Fig. 8). Consequently, the VNI model seems to be superior to the VNI+ one in reproducing the observed absorption spectrum recorded at $\mathrm{pH} 8.3$ for native VCPO. In the spectrum calculated for VNI model we observe one intense peak near $3.95 \mathrm{eV}$ and two most intense features at about $4.30 \mathrm{eV}$. The corresponding features in the case of VNI+ model lie at about 4.25 and $4.50 \mathrm{eV}$. In absorption experiment maximum of the band lies at $3.94 \mathrm{eV}$ and strong background absorption starts at $4.43 \mathrm{eV}$. However, irrespective of the protonation state of the apical oxygen, the character of the transitions appearing in the absorption spectra is almost the same for the two models. The spectra start with $\mathrm{His}_{496} \pi \rightarrow \mathrm{V}$ 3d transitions (for VNI first three peaks, for VNI+ peaks $1,3,4$, and 5) which are accompanied by oxygen's $2 \mathrm{p} \rightarrow \mathrm{V}$ 3d transitions when we move to higher energies. In addition, the second most intense feature calculated for the VNI model (at $4.37 \mathrm{eV}$ ) is dominated by the $\mathrm{His}_{496} \pi \rightarrow$ $\mathrm{V}$ 3d transition. Moreover, these calculations predict a noticeable shift (ca. $0.2 \mathrm{eV}$ ) in absorption maximum upon protonation of the apical hydroxide group and it is interesting to notice, that absorption maximum of holochloroperoxidase at $\mathrm{pH} 5$ lies at $4.00-4.06 \mathrm{eV}$ (shift of ca. $0.1 \mathrm{eV}$ ). Thus we propose a hypothesis, that the apical hydroxide group is protonated at $\mathrm{pH}$ 5.0, which is optimal for catalytic activity, and that the observed shift in absorption maximum is caused by protonation equilibrium engaging the oxygen-based apical group.

As far as the peroxide-bound form of chloroperoxidase is concerned, one can observe in Figure 9 a significant drop in oscillator strengths for IDU compared to the VNI model. This is also observed in experiment, where the extinction coefficient at 315 $\mathrm{nm}\left(3.94 \mathrm{eV}\right.$ ) changes from $2.8 \mathrm{mM}^{-1} \mathrm{~cm}^{-1}$ (for
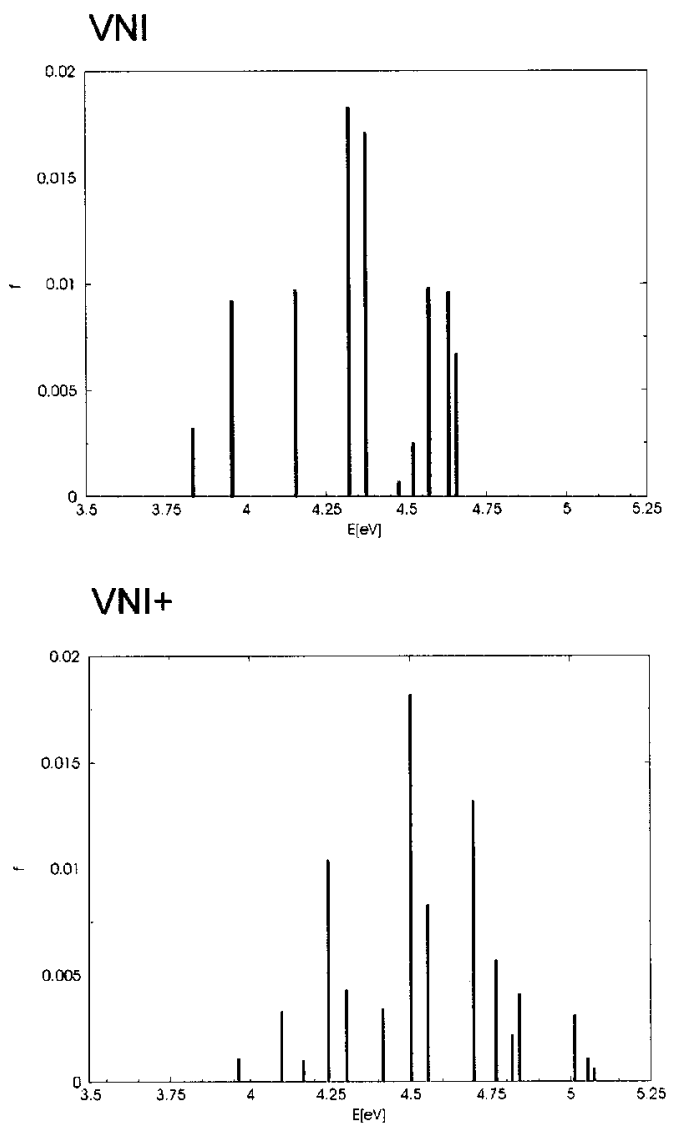

FIGURE 8. Calculated (TDDFT) electronic spectra for $\mathrm{VNI}$ and $\mathrm{VNI}+$ models. 
IDU

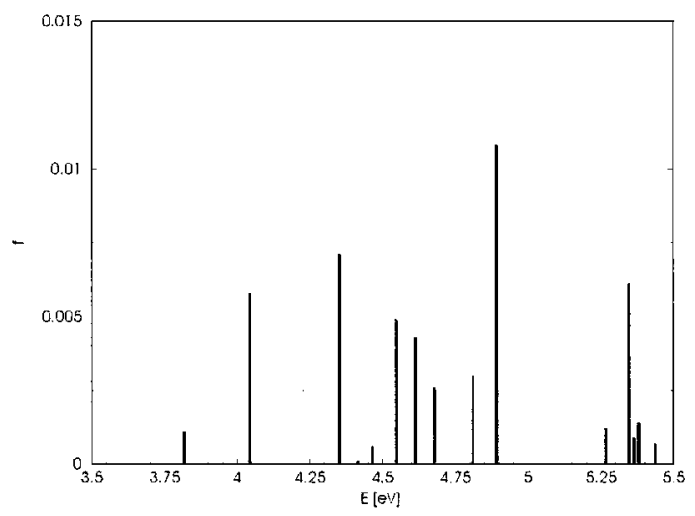

IDU+

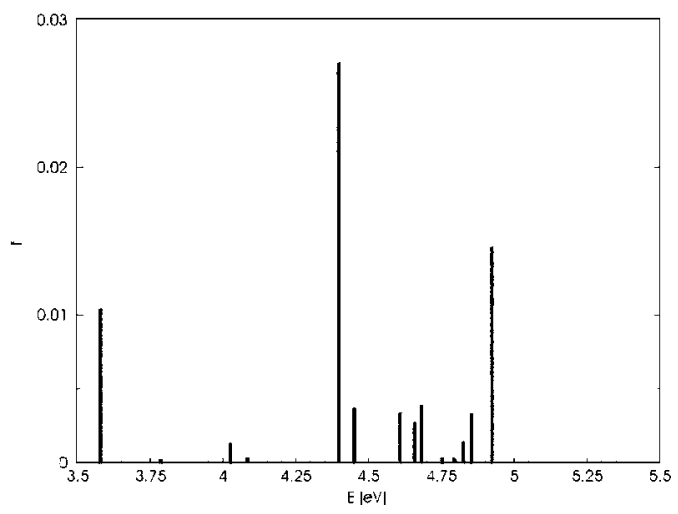

FIGURE 9. Calculated (TDDFT) electronic spectra for IDU and IDU+ models.

holo-VCPO) to $0.7 \mathrm{mM}^{-1} \mathrm{~cm}^{-1}$ for peroxide-bound form of VCPO. For the IDU model, the lowest energy transitions have a mixed charge-transfer character. The HOMO orbital engaged in these excitations is a mixture of $\mathrm{His}_{496} \pi$ and peroxide (out of the $\mathrm{V}-\mathrm{O}-\mathrm{O}$ plane) $\pi^{*}$ orbitals. However, only the protonated model, IDU+, predicts the appearance of absorption at significantly lower energy than the models of the holoenzyme. In experiments, a small peak at $384 \mathrm{~nm}(3.23 \mathrm{eV})$ is observed for this form of VCPO. Quite interestingly, the excitation at $3.58 \mathrm{eV}$ for IDU+ corresponds to the pure $\mathrm{His}_{496} \pi \rightarrow \mathrm{V}$ 3d charge-transfer transition with no peroxide contribution. On the other hand, the most intense peak at $4.40 \mathrm{eV}$ corresponds to the peroxide $\pi^{*}$ (in $\mathrm{V}-\mathrm{O}-\mathrm{O}$ plane) $\rightarrow$ V 3d CT transition. Thus, the experimental spectrum for peroxide-bound form of VCPO might be explained if one assumes a protonation equilibrium between IDU and IDU+ type centers. A minority of protonated species would give rise to the small peak at $3.23 \mathrm{eV}$, while the most abundant deprotonated form would cause a decrease in the absorption at $3.94 \mathrm{eV}$. This hypothesis is corroborated by ${ }^{17} \mathrm{O}$ NMR studies for the peroxide-bound form of bromoperoxidase from Ascophyllum nodosum, an enzyme very similar to VCPO. In their work, Căsný et al. demonstrated the existence of peroxides bound to the active site [32] in a symmetrical and asymmetrical fashion. The latter was proposed to be operational for singly protonated peroxide group.

\section{Conclusions}

The results of theoretical calculations for reliable models of active sites in VCPO reported here allowed for the interpretation of the observed spectral features. First of all, the character of the electronic transitions was identified as a charge-transfer one. As these transitions involve $\mathrm{His}_{496}$, the experimentally established fact that this ligand is necessary for the absorption is now fully understood. Moreover, the shift in absorption maximum upon $\mathrm{pH}$ change was explained as well as spectral changes upon peroxide binding to vanadium atom. Accordingly, it seems that the models employed here are reliable enough to be used in catalytic reaction mechanism study, which are already in progress in our laboratory.

\section{ACKNOWLEDGMENTS}

This study was sponsored by the Polish State Committee for Scientific Research (grant 3 T09A 130 19). Computing facilities were supported by a grant from the State Committee for Scientific Research (KBN/SGI_ORIGIN_2000/UJ/042/1999).

\section{References}

1. Butler, A.; Walker, J. V. Chem. Rev. 1993, 93, 1937-1944.

2. Messerschmidt, A.; Wever, R. Proc. Natl. Acad. Sci. USA 1996, 93, 392-396.

3. Messerschmidt, A.; Prade, L.; Wever, R. Biol. Chem. 1997, 378, 309-315.

4. Macedo-Ribeiro, S.; Hemrika, W.; Renirie, R.; Wever, R.; Messerschmidt, A. J. Biol. Inorg. Chem. 1999, 4, 209-219.

5. Renirie, R.; Hemrika, W.; Piersma, S. R.; Wever, R. Biochemistry 2000, 39, 1133-1141.

6. Hamstra, B. J.; Colpas, G. J.; Pecoraro, V. L. Inorg. Chem. 1998, 37, 949-955.

7. Clague, M. J.; Keder, N. L.; Butler, A. Inorg. Chem. 1993, 32, $4754-4761$. 
8. Colpas, G. J.; Hamstra, B. J.; Kampf, J. W.; Pecoraro, V. L. J. Am. Chem. Soc. 1996, 118, 3469-3478.

9. Gross, E. K. U.; Ullrich, C. A.; Grossmann, U. J. In Density Functional Theory; Gross, E. K. U.; Dreizler, R. M., Eds.; Plenum Press: New York, 1995; p 149.

10. Casida, M. E. In Recent Developments and Applications of Modern Density Functional Theory; Seminario, J. M., Ed.; Elsevier: Amsterdam, 1996; p 391.

11. van Gisbergen, S. J. A.; Groeneveld, J. A.; Rosa, A.; Snijders, J. G.; Baerends, E. J. J. Phys. Chem. A 1999, 103, 6835.

12. Rosa, A.; Baerends, E. J.; van Gisbergen, S. J. A.; van Lenthe, E.; Groeneveld, J. A.; Snijders, J. G. J. Am. Chem. Soc. 1999, 121. 10356.

13. Brocławik, E.; Borowski, T. Chem. Phys. Lett. 2001, 339, 433-437.

14. Borowski, T.; Król, M.; Chruszcz, M.; Brocławik, E. J. Phys. Chem. B 2001, 105, 12212-12220.

15. Conte, V.; Bortolini, O.; Carraro, M.; Moro, S. J. Inorg. Biochem. 2000, 80,41-49.

16. Bonchio, M.; Bortolini, O.; Conte, V.; Moro, S. Eur. J. Inorg. Chem. 2001, 2913-2919.

17. Bortolini, O.; Carraro, M.; Conte, V.; Moro, S. Eur. J. Inorg. Chem. 1999, 1489-1495.

18. Frisch, M. J.; Trucks, G. W.; Schlegel, H. B.; Scuseria, G. E.; Robb, M. A.; Cheeseman, J. R.; Zakrzewski, V. G.; Montgomery, J. A., Jr.; Stratmann, R. E.; Burant, J. C.; Dapprich, S.; Millam, J. M.; Daniels, A. D.; Kudin, K. N.; Strain, M. C.; Farkas, O.; Tomasi, J.; Barone, V.; Cossi, M.; Cammi, R.; Mennucci, B.; Pomelli, C.; Adamo, C.; Clifford, S.; Ochterski, J.; Petersson, G. A.; Ayala, P. Y.; Cui, Q.; Morokuma, K.; Malick, D. K.; Rabuck, A. D.; Raghavachari, K.; Foresman, J. B.; Cioslowski, J.; Ortiz, J. V.; Stefanov, B. B.; Liu, G.; Liashenko, A.; Piskorz, P.; Komaromi, I.; Gomperts, R.; Mar- tin, R. L.; Fox, D. J.; Keith, T.; Al-Laham, M. A.; Peng, C. Y.; Nanayakkara, A.; Gonzalez, C.; Challacombe, M.; Gill, P. M. W.; Johnson, B.; Chen, W.; Wong, M. W.; Andres, J. L.; Gonzalez, C.; Head-Gordon, M.; Replogle, E. S.; Pople, J. A. Gaussian 98, Revision A.6; Gaussian, Inc.: Pittsburgh, PA, 1998.

19. Cerius ${ }^{2}$ Modeling Environment, Release 4.5; Molecular Simulations, Inc.: San Diego, 2000

20. Schaftenaar, G. MOLDEN; CAOS/CAMM Center: Nijmegen, The Netherlands.

21. Becke, A. D. J. Chem. Phys. 1993, 98, 5648.

22. Hay, P. J.; Wadt, W. R. J. Chem. Phys. 1985, 82, 270.

23. Hay, P. J.; Wadt, W. R. J. Chem. Phys. 1985, 82, 299.

24. Dunning, T. H.; Hay, P. J., Jr. In Modern Theoretical Chemistry; Schafer, H. F., III, Ed.; Plenum: New York, 1976.

25. Bytheway, I.; Wong, M. W. Chem. Phys. Lett. 1998, 282, 219-226.

26. Weiner, S. J.; Kollman, P. A.; Case, D. A.; Singh, U. C.; Ghio, C.; Alagona, G.; Profeta, S., Jr.; Weiner, P. J. Am. Chem. Soc. 1984, 106, 756 .

27. Serrano-Andrés, L.; Fülscher, M. P.; Karlström, G. Int. J. Quant. Chem. 1997, 65, 167-181.

28. Pierloot, K.; De Kerpel, J. O. A.; Ryde, U. J. Am. Chem. Soc. 1997, 117, 218-226.

29. Seijo, L.; Barandiaran, Z.; McClure, D. S. Int. J. Quant. Chem. 2000, 80, 623-635.

30. O’Brien, T. A.; Rack, P. D.; Holloway, P. H.; Zerner, M. C. J. Lumin. 1998, 78, 245-257.

31. Rehder, D.; Schulzke, C.; Dau, H.; Meinke, C.; Hanss, J.; Epple, M. J. Inorg. Biochem. 2000, 80, 115-121.

32. Căsný, M.; Rehder, D.; Schmidt, H.; Vilter, H.; Conte, V. J. Inorg. Biochem. 2000, 80, 157-160. 